\title{
Perspectives on Women: A Case Study of a University Course on Public Television
}

\section{June R. Landsburg Anita Clair Fellman}

\begin{abstract}
This case study on the development and presentation of a university course on a public television channel demonstrates some of the significant differences between a classroom course and a broadcast television course. The interaction between Simon Fraser University and British Columbia's Knowledge Network are described in the context of the course Perspectives on women: An Introduction to Women's Studies. The paper describes how public television influenced the course design, particularly those components of the course which had potential for controversy.
\end{abstract}

Learning at a distance can be enhanced by broadcast television but a third party, the television network, is interposed between teacher and learner. This paper looks at the interactions between and different perspectives of university and network in providing televisionbased learning experiences for both formally enrolled students and a general viewing audience. It also identifies how public television influences the design of a course. This is a case study: Simon Fraser University, B.C.'s Knowledge Network and a course titled Perspectives on Women: An Introduction to Women's Studies.

\section{Simon Fraser University and the Knowledge Network}

The distribution of educational television to supplement and enhance distance education has developed in British Columbia since the formation of the Knowledge Network in 1980. Over a third of the province's population is scattered in small cities, towns, and individual homesteads over the rugged 366,000 square miles of B.C. land mass. This pattern of widely dispersed settlement and the expense and difficulty of transportation cause great difficulty in the provision of equitable educational services across the province. In part to reduce this imbalance, the Knowledge Network (also called KNOW) operates a single channel public television service distributed by satellite to local CATV systems.

Currently 250 communities with 90 per cent of the population of B.C. receive the

June R. Landsburg is Director of the Applied Sciences Programs in Continuing Studies at Simon Fraser University in Burnaby, British Columbia. Formerly, she was the cofounder of instructional television at Carleton University in Ottawa and served on the AMTEC Board of Directors from 1979-1982. Anita Ciair Fellman is an historian, teacher and writer and co-editor (with Veronica Strong-Boag) of Rethinking Canada: The Promise of Women's History.

CJEC, VOL. 15, NO. 3, PAGES 191-197, ISSN $0710-4340$ 
Knowledge Network. An average of 440,000 people, representing 210,000 households watch KNOW each week. This is equal to 20 per cent of the households in the province. KNOW provides 14 hours of programming a day, seven days a week. Children's programs are offered from 9-11 a.m. and 4-5:30 p.m. weekdays with non-credit telecourses for the adult population offered through late morning and early afternoon. Post-secondary credit courses are telecast during prime time in the evening and general interest programming after 8 p.m. Total enrollment for Spring 1985 in credit and non-credit telecourses was 9,200.

Simon Fraser University (SFU), with its innovative continuing studies program and an expanding centre for distance education, is an active participant in post-secondary programming on the Knowledge Network. Over the past five years, Simon Fraser's programming has grown ten-fold. Current levels are 275 hours of television annually, split between credit and non-credit programming. Some of these programs supplement the print base of SFU's distance education courses, while other television programs form the core around which a distance education course has been structured. Still others provide professional development for teachers. Special courses, delivered almost entirely by TV, and some general education courses complete the list.

A few examples will illustrate the approach used. A non-credit series, first aired in Spring 1983, dealt with the culture of bees in B.C. These programs were produced at SFU and, when aired on KNOW, were supplemented by on-air "phone-in" sessions. Another example, a third year history telecourse, World War II, was based on the Thames television series "The World at War", augmented by additional material featuring the course instructor and produced by SFU. To supplement a women's studies credit course based on print materials, Perspectives on Women, an eight-part television series, utilized selected commercial films plus live panel discussions hosted by the course instructor. These also incorporated broadcast interaction with the viewing audience by telephone.

As we know, there are both advantages and disadvantages in the use of television for the students but these extend to the institutions also. The dictates of TV and the need for inter-institutional coordination impinge on university autonomy. For example, the limits to available air time conflict with the desire to present a large diversity of courses. A conflict also exists between the technical and production standards expected of broadcast TV programs and those actually needed for successful learning. There is an extreme cost difference between these two standards, and broadcast standards cannot be achieved within current university budgets. This list could be expanded but the nature of the interactions between the educational institution and the television network are complex and perhaps better described through an example.

\section{Perspectives on Women: An Introduction to Women's Studies}

The objective of the Distance Education course Perspectives on Women is, like the on-campus credit course it replicates, to introduce students to a range of key questions about the experiences of women in Canada today, in the European past and, briefly, in markedly different cultures. As well, the course aims to identify, organize and critique a substantial body of often contradictory opinion and data regarding women. By exposing the students to this material, it is hoped that they will take a more active role in their own education.

The intended clientele for the course has expanded with time. Experience with oncampus women's studies courses, as well as requests for a course by people outside the Vancouver area, initially indicated that interested housewives, young women in the labour 
force and students would form the bulk of the audience. Another group, males, in their 20's and 30's, intrigued by studying women but wary of taking an on-campus course, were perceived as a substantial minority. However, with the use of television as one of the course media, the audience has expanded to include both occasional and loyal viewers of both sexes and a considerable range of ages who follow the television portion of the course without registering for credit.

Planning and production took two years. The planning process first involved identification of the appropriate format by which the course would closely replicate the varied educational techniques used in the on-campus course. Discovering that one medium would not suffice, the course author decided to use a combination of media: print, audiotape, television, letting each medium do what it does best. All these were used to meet the diverse needs of students who leam best in different ways.

Each medium used required varying degrees of cooperative planning. The printed study guide, while formally the work of one person, drew on semesters of feedback and response from students in the on-campus course. The course author collaborated, as she would later with the television guests as well, with the audiotape discussants to arrive at a mutuallyagreed upon focus of discussion. The television portion of the course, bringing in the resources of the provincial educational network, required the most elaborate planning. Personnel of the Knowledge Network were involved in developing that part of the course from the beginning. As it was not always easy to reconcile the Network's concern with production values and technical standards and the University's focus on educational values, good liaison between the University and the Knowledge Network was invaluable. The innovative content of some of the programs posed distinct challenges which caused the Network to reassess its responsibilities to its audience and the University to realize the differences between the classroom and public television.

With the decision to utilize television for teaching of Perspectives on Women, new complexities were introduced to the implementation of the course. First was the question of audience. Rather than speaking solely to a discrete audience of those who had expressed interest in the subject by registering in the course, two other audiences would be gained: those who might be deeply interested and those who would be only casually attentive. Thousands would drop by, either regularly or sporadically, by selecting the KNOW channel.

The task was to give all three of these audiences something worthwhile to watch. The casual viewer might be enticed by the production of a good, lively show on topics of general interest. While each show was part of a cumulative whole, it was also enjoyable and instructive on its own. It was anticipated that there would also be a sizeable audience of people who, while not enrolled, were vitally interested in the topic. Consequently a viewer's guide to the series of eight television programs was produced. For each program this guide provided enough information to create some background for the film and for the discussion. As with the credit students, these viewers were encouraged to put their own experiences into context, as well as offered a series of questions to ask about situations distant from their own. The guide was printed free of charge by a large local union, and distributed through its offices as well as through the University. The registered student also had much to gain from the television series. Each program was as integrally related to the course as any reading assignment, and provided the student with vivid visual images to reinforce the points made in the readings and discussions. The students found that the course author became less of a disembodied presence when they actually saw her on television, hosting the series. 
The other complexity in implementation stemmed from the different standards of discourse that apply to the classroom as opposed to those of a publicly funded television network. Perspectives on Women deals with some topics that are new in public discourse. Only now are we becoming accustomed to discussing pornography or rape in a serious, nontitillating manner in public. Such topics are somewhat less problematic in the classroom. For instance, the National Film Board film "Not a Love Story" has been shown in the classroom ever since it was released, whereas it had never been shown on television in British Columbia. If the distance education course was to be equivalent to the on-campus course, a way of dealing with this film on television had to be found. The program on pornography and another one on rape were managed by placing the issues in context, by choosing the guests carefully and by focusing the discussions very precisely. The viewing audience was also given an opportunity to respond by the provision of an interactive segment. One other program was also especially innovative, although not controversial in the same sense. During the program on Women in Popular Culture, a film theorist showed and analyzed the entire Hollywood "woman's" film "The Snakepit."

The learning strategies for the course were predicated on the goal of encouraging women to view themselves as actors in their own destinies, rather than as passive victims. Educationally, this translated into urging students to take an active role in the course. For instance, experts utilized as participants in discussions rather than as lecturers, were not designated as final authorities but as resource people whose points of view were to be identified and analyzed. The television series frequently used "ordinary" people as expert guests who could speak on certain topics with the weight of experience or considerable study and thought. The viewer's guide encouraged the viewer to watch the series, not passively, but with questions in mind. The interactive segments of the television programs permitted the registered student or the casual viewer to call in with their comments. The series host asked for -- and received -- written and telephone reactions to each program. The audiotapes were in the form of discussions, exchanges between two people, rather than lectures. In addition to more conventional assignments, registered students were asked to keep a reading journal to record their responses to the course materials. The course tutor held both telephone and inperson office hours to allow students frequent opportunities for questions and comments.

It was not just the influence of television on the nature and design of the course that made the preparation of Perspectives on Women a complex challenge for all those involved. Finding suitable films and acquiring broadcast rights required much effort by KNOW and SFU. This took a whole year in the case of one particular feature film. Designing and formatting the course had to accommodate the "learning systems design" perspective of the Knowledge Network while acknowledging the autonomy of the University. Not surprisingly there was a need for an ongoing liaison person to satisfy both SFU and KNOW. University responsibilities were writing the course and providing scripts, guests and direction for TV, while KNOW undertook technical direction and production services. Overall coordination and the executive production function were the responsibility of the Coordinator, Educational Telecommunications Projects, at SFU.

With the active involvement of the course author and host, the executive producer, the print editor, the television director, the technical producer and many others who made smaller specialized contributions, there was much daily detailed interaction between personnel at KNOW and SFU. In such projects, this interaction must be effective in accommodating many different constraints. For example, scarcity of air time is a reality. Schedules 
must be negotiated, often before production has been completed because of a requirement for air time bookings seven months in advance of the first broadcast.

Ideally, all courses remain open to the suggestions of their constituents. When a course enters the living rooms of thousands of de facto students, the evaluation process takes on complexities that are missing from the less-monitored classroom or from the traditional distance education format. The eight television programs of Perspectives on Women (incorporating generally an introduction by the course author as host, a film, a panel discussion, on-air 'phone-in interaction by viewers and, finally an off-air 'phone-in session) were first presented in Fall 1984. The television series, according to the Nielsen Index, attracted some 20,000 people weekly. The host's request that viewers call or write with questions and comments resulted in several hundred letters and telephone calls from men and women. Most of these were complimentary. Some people just wanted to chat, to comment with wonder that so many of the programs described their lives. Others wanted information on self-help or community or political action groups. A few wanted suggestions for reading materials.

Course evaluation forms completed by registered students were the formal means by which it was assessed that Perspectives on Women had been well received. There were numerous other means, however, of ascertaining people's reactions and their suggestions for improvements. The tutor was the link to the registered students. Students made full use of her office hours, bombarding her with questions when they found an assignment ambiguous or a point contentious. It was they who suggested some changes in the format of the assignments, and it was their questions which caused the addition of a fourth audiotape to explicate some reading material that they found especially difficult.

The Knowledge Network asked to be kept abreast of student and viewer evaluation of the series. The Network's reaction to the one program which elicited a mixed response highlighted the tensions that can arise between university and network, each with its own circumstances, priorities, traditions, and mandate. The showing of "Not a Love Story" made the program on pornography problematic for some viewers and hence for the Network as well. That film evokes a viewer response which illustrates to an extreme how film and television reach beyond the presentation of facts. Indeed, this was a key reason for showing "Not a Love Story" on Perspectives on Women which sought to use the medium of television itself to critique the impoverished images of women on television. Initially at least, this educational rationale was less compelling to the Network than was the prospect of irate viewers protesting the presence of sexually explicit images on their screens, despite the critical stance taken by the film toward those images.

Just prior to the airing of "Not A Love Story", the Knowledge Network expressed concern about potential public reaction but the broadcast went ahead in the planned format. In program information material and just before the beginning of the program a "due to the content, viewer discretion is advised" disclaimer was used in both verbal and visual forms. Nevertheless, several dozen members of the public made negative responses to the University, the Network and perhaps even to elected representatives.

Predictably, perhaps, the Network was troubled and raised the issue of "mutual responsibilities when our electronic classroom has no closed door and is available in almost every home." It was led to concerns about the relative roles of university and network, as well as the nature of the "shared moral authority" of the two organizations. In spite of its awkward situation, KNOW did support the airing of reruns of Perspectives on Women in the 
following semester but with certain requirements concerning the program on pornography: a 9:30 p.m. time slot and a new learning design incorporating (1) stronger viewer warnings, (2) running warnings during "Not a Love Story" and (3) a live interactive session even on repeat broadcasts. As a consequence, the University withdrew Perspectives on Women from the planned schedule until a new format could be devised.

Further investigation showed that "Not a Love Story" had been aired previously in Ontario and Alberta on cable television (Super Channel, available to "pay TV" subscribers) with disclaimers and a pre-recorded introduction and discussion. Audience reaction had been excellent.

During this time, viewer reaction continued to be received at the University. Most of it was positive, with callers interested in serious discussion of the issues presented. Parents concerned with possible negative influences on their children were advised not to allow them to watch the program

Several months of discussion between the University and Network led to an agreement, including additional financing, to tape a panel discussion on Not a Love Story which would include interaction between a studio audience (as a surrogate home viewing audience) and the panel. Subsequently, Perspectives on Women was aired on the Knowledge Network during Summer 1985 and again that Fall, and is planned for both Summer and Fall 1986. All programs now start at 10 p.m. The series host continues to be available for 'phone discussions which have now run well into the hundreds. Interestingly, these off-air discussions are far superior in terms of thoughtfulness to those experienced on-air in the original program.

The University personnel involved in the series concluded that the revised program was indeed more sensitive to the feelings of possibly isolated individuals watching a television program on a troubling issue. The Network's administrators, having made what they deemed to be a reasonable effort to meet viewers' complaints, came to an explicit recognition that education, even on public television, might well involve the presentation of ideas that are both contentious and discomforting to some people. Both University and Network learned from the experience.

The measured viewing audience of 20,000 during the first distribution on KNOW, plus the decisions to re-broadcast the series twice a year, are measures of the success of Perspectives on Women. Yet another is provided by the course evaluations. To quote from a comment on the pomography program:

We were quite shocked by some of the film's content, but we were impressed by the way in which the film provided a critique of pornography and we also found the panel discussion afterward stimulating and enlightening.

And, responding to a program on the changing careers of women, another stated:

It has expanded my vision of "what to be when I grow up" and given me a lot of confidence to now begin to look up avenuesthat could be work that I would be interested in.

\section{Conclusions}

The experience of both University and Network with Perspectives on Women was 
certainly educational for both institutions. Many individuais were involved in this complex, multi-faceted undertaking. That alone required active coordination and a good understanding of the other's problems, but the intrinsic differences between the role of the Network and the role of the University exacerbated communication dilemmas. It is essential that both sides appreciate the conflicting environments of the classroom and public television.

Potential controversy over the pomography program, together with the sensitivity surrounding rape, served to amplify the differences between the roles of the two institutions. The bonds of cooperation were strained but not broken and, through the experience, they were strengthened.

With a budget of $\$ 8,000$ for pre-production research and text preparation, $\$ 30,000$ for television production (including acquisition of broadcast rights to films) and $\$ 6,000$ for additional production after the first airing, the project was not overly expensive. Of course, most of the "people costs" do not appear in this budget, nor do the wear and tear associated with the negotiation of the necessary compromises between network and university.

By its very nature, the value of a case study is found in its subtieties rather than in overt conclusions. A moral to be drawn from this story, however, is the placing a public television network between teacher and student intrudes dramatically into the educational process. Much more is involved than a learning paradigm. 